\title{
A CONTRIBUIÇÃO DAS NARRATIVAS ORAIS DE HISTÓRIAS PARA APRENDIZAGEM: A VISÃO DO PROFESSOR ALFABETIZADOR
}

\author{
THE CONTRIBUTION OF ORAL STORY NARRATIVES TO \\ LEARNING: THE VISION OF THE LITERACY TEACHER
}

\author{
D Claudia Maria Petchak Zanlorenzi \\ Pós doutora em Educação \\ Universidade Estadual do Paraná- UNESPAR. \\ União da Vitória, Paraná - Brasil \\ aecmari@gmail.com \\ Paola Helena Muxfeldt Morandi da Silva \\ Graduanda de Pedagogia \\ Bolsista de Iniciação Científica do Conselho Nacional de Desenvolvimento Científico e Tecnológico - \\ $\mathrm{CNPq}$ \\ Universidade Estadual do Paraná - UNESPAR. \\ União da Vitória Paraná- Brasil. \\ paolamuxfeldt@hotmail.com
}

\begin{abstract}
Resumo: Diferente da dramatização ou da leitura, o ato de contar histórias é uma rica possibilidade simbólica. As narrativas de histórias para crianças em espaços institucionais, revelam além de práticas pedagógicas pretextais a possibilidade de um espaço para estudo para a imaginação criativa, a oralidade, entre outros. Diante disso, qual é a visão do professor sobre a contribuição das narrativas orais para a aprendizagem dos alunos? O objetivo foi investigar a opinião dos professores sobre a contribuição das narrativas orais para a aprendizagem e quais os aspectos dessa aprendizagem são levantados pelos professores. A pesquisa de cunho qualitativo, a partir de pesquisa bibliográfica e de campo, teve como sujeitos professores da pré escola (infantil 5) e de classes de alfabetização ( $1^{\circ}$ ano) de um município do sul do Paraná. Foi possível verificar quais as possíveis fragilidades e lacunas relacionadas ao trabalho com narrativas orais.
\end{abstract}

Palavras-chave: narrativas orais de histórias; aprendizagem; ensino; professores; anos iniciais.

Abstract: Unlike drama or reading, the act of telling stories is a symbolic possibility. The story narratives, especially for children in institutional spaces, reveal much more than just pre-textual pedagogical practices but the possibility of a space for study, such as creative imagination, orality, among others. Given this, what is the teacher's view about the contribution of oral narratives to student learning? The purpose of this project is to investigate the opinion of teachers about the contribution of oral narratives to learning and what aspects of this learning are raised by teachers. This research will be qualitative, based on bibliographic research and field research, having the preschool teacher (infant school grade 5) as subjects and literacy classes (1st year), in the municipality of União da Vitória. This research aims to check what are the possible weaknesses and gaps related to the I work with oral narratives.

Keywords: oral storytelling; learning; teaching; teachers of early years.

Para citar - ABNT NBR 6023:2018

ZANLORENZI, Claudia Maria Petchak; SILVA, Paola Helena Muxfeldt Morandi da. A contribuição das narrativas orais de histórias para aprendizagem: a visão do professor alfabetizador. Cadernos de Pós-graduação, São Paulo, v. 20, n. 1, p. 218-231, jan./jun. 2021. Disponível em: https://doi.org/10.5585/cpg.v20n1.19343. 
Introdução

É unânime a importância das narrativas orais de história ou contação de histórias e muitos são os autores brasileiros que se dedicam ao estudo dessa arte. Entre eles destacam-se Tahan (1964), Girardello (2004, 2007, 2014), Sisto (2004, 2005), Coelho (1990) e Machado (2004), que apontam as potencialidades desenvolvidas e das questões mais práticas que envolvem a ação de contar histórias.

Em meio a possibilidade de contribuição dos momentos de narrativas orais, destaca-se o desenvolvimento das funções cerebrais superiores como a linguagem, o pensamento, a memória e a abstração. Quanto mais o aluno participa de momentos de narrativas orais, mais seu pensamento se torna lógico e, consequentemente, mais reflete sobre a linguagem, pois a exposição oral é um “[...] grande meio de expressão e de atividade. [...] enquanto prática social é inerente ao ser humano, [...] a porta de nossa iniciação à racionalidade.” (MARCUSCHI, 2003, p. 35).

As narrativas de histórias, principalmente para crianças em espaços escolares institucionais, revelam muito mais do que apenas práticas pedagógicas pretextais, pois oportunizam um estudo que trata da contribuição desta estratégia de ensino para a aprendizagem. Diante do exposto, inserindo a contação de histórias como protagonista para aprendizagem, a presente pesquisa tem como problemática: qual é a visão do professor sobre a contribuição das narrativas orais para a aprendizagem dos alunos?

O presente artigo tem por finalidade apresentar um projeto de pesquisa que teve por objetivo geral investigar a visão dos professores dos anos iniciais sobre a contribuição das narrativas orais de histórias para a aprendizagem dos alunos. A pesquisa foi de cunho qualitativo, com bibliográfica e pesquisa de campo. Para pesquisa bibliográfica foram utilizados autores que discutem sobre narrativas orais, e a pesquisa de campo teve como sujeitos os professores da pré-escola (infantil 5) e de classes de alfabetização ( $1^{\circ}$ ano), da rede pública municipal de ensino, de um município do sul do Paraná. Para a coleta de dados utilizou-se um questionário via formulário do Google Docs, por intermédio da Secretaria Municipal de Educação, o qual teve a anuência do Comitê de Ética ${ }^{1}$.

Pretendeu-se com essa pesquisa verificar quais as possíveis fragilidades e lacunas relacionadas ao trabalho com narrativas orais de histórias, bem como dar profundidade conceitual. Outrossim, as reflexões provenientes dos estudos proporcionaram temáticas para futuros grupos de estudos e proposições de formação docente.

${ }^{1}$ Parecer 4.197.511, de 06 de agosto de 2020. Comitê de Ética (UNESPAR). 


\section{Narrativa Oral e o Desenvolvimento Humano}

Tratar da narrativa oral é compreender o seu espaço enquanto constituição do ser humano. Além de ser considerada como uma forma de arte, e como expressão da criatividade humana, é preponderante compreendê-la como necessária à organização social.

Parte-se do pressuposto que o homem é um ser histórico, que ao se relacionar com a natureza, transforma-a e é transformado. Nesse paradoxo, natureza-homem, o homem vai se humanizando, na qual a sua própria natureza e as condições materiais são constituintes desta transformação. Para tanto, o trabalho é sua atividade vital consciente. "A atividade vital consciente distingue o homem imediatamente da atividade vital animal. Justamente, (e) só por isso, ele é um ser genérico.” (MARX, 2004, p. 84).

Nesta unidade contraditória, entre a capacidade biológica elementar para responder aos estímulos e os determinantes do meio, é que se processa a atividade fundante, o trabalho, pois o homem na sua hominização nasce com o potencial para a humanização, ou seja, a "[...] superação do ser hominizado em direção ao ser humanizado, processo que, para se efetivar, demanda a inserção de cada indivíduo particular na história do gênero humano.” (MARTINS, 2013, p. 10).

Neste sentido é que a adaptação natural do homem ultrapassa as questões que lhe são elementares (memória, atenção, percepção naturais), e, pelo intercâmbio com a natureza e as condições materiais de existência, a atividade torna-se socializada, ultrapassando as necessidades biológicas, tornando-se humanizadas (memória lógica, atenção voluntária e formação de conceitos). Com efeito, esse imbricamento entre o natural e o social não pode ser considerado na ascensão do natural rumo ao social, mas na relação dialética permanente, promovendo uma síntese histórica do homem.

Para tanto, a utilização de instrumentos e ferramentas que possibilitem “[...] a produção dos meios para a satisfação de suas necessidades, a produção da própria vida material, [...] simplesmente para manter os homens vivos." (MARX; ENGELS, 2007, p. 33), fará que a atividade humana torne-se cada vez menos elementar e mais complexa. A produção dessas necessidades irá promover o aparecimento de novas necessidades criando novas relações sociais e intercâmbio entre os homens.

Para a efetivação dessa produção é necessária a antecipação do que será concretizado. Essa dimensão teleológica, o que difere o homem dos outros animais, impulsiona a imaginação criativa, uma vez que "No final do processo de trabalho, chega-se a um resultado que já estava presente na representação do trabalhador no início do processo, portanto, um resultado que já existia idealmente." (MARX, 2017, p. 327). 
O existir idealmente é fruto do planejar, do intencionar, reelaborar, ou seja, imaginar a partir da realidade do sujeito para então retornar a própria realidade, “[...] mas já com uma nova força ativa que a modifica. Assim é o círculo completo da atividade criativa da imaginação." (VIGOTSKI, 2018, p. 28-29).

Diante do exposto, considera-se que a intencionalidade só é possível a partir da imaginação criativa e esta é resultado das ações concretas do sujeito, ou seja, quanto mais ricas e diversas as oportunidades experienciais, maior o arsenal de imaginação criativa, haja vista que essa "é um momento totalmente necessário, inseparável, do pensamento realista.”(VIGOTSKI, 1999, p. 128). Afirma-se que a imaginação criadora não é algo inato, mas sim a relação entre a subjetividade e objetividade, ou seja, daquilo que o sujeito tem em sua memória das suas ações experienciais concretas para então modificar a realidade, a unidade dialética entre conservação e transformação. "É exatamente a atividade criadora que faz do homem um ser que se volta para o futuro, erigindo-o e modificando o seu presente." (VIGOTSKI, 2018, p. 16).

A humanização do homem só é possível também pela imaginação criadora, que está intimamente relacionada com o intercâmbio entre os homens. Todo o mundo da cultura, o socializado, o modificado, o novo, o humanizado, ou seja, todo o produto originário do trabalho feito pelo homem é proveniente da imaginação.

$\mathrm{Na}$ mediação desse intercâmbio, nasce a linguagem, a representação dialética entre os aspectos subjetivos e orgânicos e os objetivos e materiais dos homens, uma vez que "a interação verbal constitui assim a realidade fundamental da língua." (BAKHTIN; VOLOCHINOV, 2006, p. 125). Por meio do intercâmbio, como processo interpessoal, que a linguagem irá transformar-se em um processo intrapessoal: como instrumento de mediação e instrumento intelectual.

Trata-se, assim, do estabelecimento de um elo entre os processos de linguagem externo e interno, por meio do qual a linguagem passa a intervir diretamente no ato intelectual, requalificando a percepção, a memória, a atenção, a imaginação e os próprios sentimentos do indivíduo, conformando sua própria experiência pessoal no mundo. (MARTINS, 2013, p. 179- grifo nosso).

Pela linguagem que a imagem subjetiva se torna concreta na utilização de signos, mais especificamente, a palavra, tanto no que diz respeito à concretização do pensamento, e também como internalização de novos conhecimentos, a partir da linguagem do outro, bem como a influência no outro. 
Eis um salto qualitativo decisivo para a afirmação da natureza social humana. A imagem mental passa a ser denominada por palavras, conquistando, assim, o status de signo convertendo-se em ideia a ser expressa e transmitida pela forma de juízos e conceitos. (MARTINS, 2013, p. 10 - grifo do autor).

A imaginação criativa e a linguagem são primordiais para a compreensão dos aspectos que envolvem a humanização dos sujeitos. Nelas residem o cerne dessa humanização.

A linguagem, especificamente, como um organismo vivo e histórico, "carrega consigo os conceitos generalizados, que são a fonte do conhecimento humano.” (LURIA, 2017, p. 26). Esses conceitos, que só são possíveis na relação com o outro, são a base para a imaginação criadora. Portanto, quanto mais experiência, mais disponibilidade de imaginação criadora, e, sendo assim, corrobora-se com Vigotski (2018, p. 25) ao afirmar sobre " [...] a necessidade de ampliar a experiência da criança, caso queira-se criar bases suficientemente sólidas para a sua atividades de criação.”, bem como para sua capacidade de abstração cada vez mais complexa. Verifica-se assim o caráter materialista e histórico da imaginação, ou seja, a partir da experiência e do processo de vivência que se dará a formação da imaginação criadora.

Em face ao exposto, afirma-se a necessidade de momentos que oportunizem as crianças vivenciarem ações que incentivem a linguagem, enquanto processo interpessoal para intrapessoal e a imaginação, enquanto a ideação do concreto. Dentre elas, destaca-se a narrativa oral de histórias, ou contação de histórias como é comumente conhecida, afirmando que essa ação, que é histórica e inerente ao sujeito, contribui efetivamente para o desenvolvimento do homem. Diante do exposto, na sequência, será tratado sobre as narrativas orais de histórias como ação formadora e a prática pedagógica.

\section{Narrativas orais e a prática pedagógica}

As formas de disseminação da informação envolvem a sociedade, iniciando com a imprensa - que é a própria história do desenvolvimento do capitalismo (SODRÉ, 1999), até as redes sociais. A comunicação tornou-se a estratégia mais rápida de descrever o imediato e o cotidiano, contribuindo para um ritmo frenético e efêmero de difundir os acontecimentos.

Nesse viés, o espaço da narrativa oral como a arte de "intercambiar experiências" (BENJAMIN, 1994, p. 198), foi perdendo espaço para os artifícios da informação em massa e da ânsia pela rapidez, em que quase nada está a serviço da narrativa, ao contrário da informação, em que os fatos já chegam devidamente explicados. (BENJAMIN, 1994).

Fruto da tradição, enquanto sabedoria, e da memória passada de geração a geração pela palavra, a narrativa oral de história tendo como seu alimento a experiência, "é uma forma artesanal de comunicação [...] como a mão do oleiro na argila do barro.” (BENJAMIN, 1994, p. 205). A livre 
interpretação de quem ouve, dado que a narrativa evita explicações e sim possibilita o desvelar do imagético, está intimamente relacionada ao contexto experiencial e criativo do ouvinte.

Já na primeira infância, identificamos nas crianças processos de criação que se expressam melhor em suas brincadeiras. A criança que monta um cabo de vassoura e imagina-se cavalgando em um cavalo; a menina que brinca de boneca e imagina-se a mãe; a criança que, na brincadeira, transforma-se num bandido, num soldado do exército vermelho, num marinheiro, todas essas crianças brincantes representam exemplo da mais autêntica e mais verdadeira criação. [...] A brincadeira infantil não é uma simples recordação do que vivenciou, mas uma reelaboração criativa de impressões vivenciadas. (VIGOTSKI, 2018, p. 18).

A partir das impressões vivenciadas, a criança vai se humanizando e a narrativa oral é uma grande possibilidade de contraponto às formas de informação que "[...] só tem valor no momento que é nova.” (BENJAMIN, 1994, p. 204).

É importante apontar que se reverbera, neste trabalho, sobre a necessidade das narrativas orais para a constituição do ser humano e a ampliação da consciência humana (MATOS; SORSY, 2009, p. 21) e que para o desenvolvimento da imaginação criativa, que a mesma possibilita, elas são primordiais. Não se desconsidera a importância da informação nas suas várias formas, todavia que a sua imediaticidade já traduzida em detalhes, pouco contribui para o imagético. Corrobora-se com Benjamin (1994, p. 203) ao afirmar que a partir da narrativa o ouvinte é "livre para interpretar a história como quiser, e com isso o episódio narrado atinge uma amplitude que não existe na informação."

Muito embora as narrativas orais de histórias não tenham um lugar de destaque, tanto quanto a mediação de leitura, elas fazem parte das práticas pedagógicas da escola, no entanto sem uma compreensão da sua função, sendo a contribuição resumida a um passatempo, volta a calma ou hora do conto na biblioteca, quando existe esse espaço na instituição escolar.

Diferentemente da mediação da leitura, na qual o foco é o visual com um texto pré-estabelecido e imagens que fazem parte da composição, a narrativa oral, tem seu foco na audição. Diante disso, desctaca-se a importância da performance do contador que harmoniosamente irá utilizar-se do seu próprio eu, das experiências com histórias e técnicas que vão lhe auxiliar.

É por meio dos gestos, da expressão facial e da entonação que as palavras vão tomando sentido, pois "[...] a palavra do contador não é apenas falada; ela é mostrada pelo corpo, pelo rosto, em cada gesto. Todo o corpo deve estar em sintonia com cada palavra proferida. "(MATOS; SORSY, 2009, p. 35). É nessa atuação que a história vai se desenrolando e dando espaço para imaginação, por isso “A história tem que ser sempre 'maior' que o contador.” (SISTO, 2005, p. 43grifo do autor). 
Diante do exposto, ao vivenciar as narrativas orais de histórias na escola, as crianças participam de momentos de formação, especificamente, o desenvolvimento da memória, comparação, generalização, análise, síntese, abstração e a linguagem, uma vez que é

[...] ouvindo histórias (lidas e também contadas livremente, inspiradas na literatura ou na experiência vivida) e vendo ouvidas as suas próprias histórias que elas aprendem desde muito cedo a tecer narrativamente sua experiência, e ao fazê-lo vão se constituindo como sujeitos culturais. (GIRARDELLO, 2004, p 10).

Para tanto, à narrativa deve ser reservado um lugar de protagonista, de formação única, uma vez que tem suas especificidades que outras formas de expressão, como a mediação de leitura, não têm, haja vista que possibilita "transmutar imagens internas em configurações e linguagem, ordenadas poeticamente.” (MACHADO, 2015, p. 16).

Entretanto, para que esse protagonismo ocorra é necessário que se compreenda de que forma podem ser desenvolvidas as narrativas orais. Neste sentido, autores como Matos, Sorsy (2009), Sisto (2005), Girardello (2004), Machado (2015), conforme suas bases epistemológicas, apontam reflexões sobre essa arte e sua manifestação como ação educativa e pedagógica.

Os autores são unânimes em apontar que a narrativa oral é uma arte ancestral e "[...] qualquer pessoa que tenha voz, algum poder de memória e uma capacidade de observação, de reflexão, e que seja capaz de tirar lições da vida é um contador de histórias em potencial.” (MATOS; SORSY, 2009, p. 37).

Para dinamizar essa ação, enquanto dialogia enunciativa, ela não pode ser relegada à coadjuvante ou passatempo e, para tanto, o professor deve dar espaço à narrativa oral com fim em si mesma e não como pretexto para algo, atividade ou para ser utilizada com fins moralizantes. Com efeito, reconhecer a identidade da narrativa oral como imprescindível para a humanização é primordial, contudo, é necessário

\footnotetext{
[...] evitar o didatismo e a lição de moral; os estereótipos da palavra e dos gestos; o maniqueísmo e os preconceitos; o óbvio, o modismo e o lugar comum. Em geral, na escola, a escolha de um texto para se contado tem quase sempre, o poder de determinar conteúdo a serem estudados. Mas, quando a história contada vem em função de instaurar um espaço lúdico, ela pode gerar um outro tipo de expectativa: não mais a da cobrança, mas a do encantamento. (SISTO, 2005, p. 23).
}

Vários aspectos devem ser levados em consideração para uma narrativa oral de história e como primeiro item, é preponderante que o professor seja um leitor ativo não só de livros, mas de objetos, gestos, pessoas, fatos, ou seja, um observador, bem como ter prazer na escuta.

Já sobre as técnicas utilizadas, é importante escolher a história que desperte emoções e estimule a imaginação. O narrador deve envolver-se com a história e para isso ele precisa sentir 
vontade e segurança em contá-la como “[...] continuadores da palavra, não como recursos estanques, enxertados na história para garantir o brilho.” (SISTO, 2005, p. 31).

Para tanto, não há necessidade de decorar a história e sim memorizá-la visualmente, pois isso possibilita a liberdade imagética do próprio contador, escolhendo gestos e palavras e

Isso não significa descuido formal, ao contrário: só o passeio atento pelas imagens da história e a pesquisa prévia dos recursos verbais e corporais mais adequados a sugeri-las às crianças pode gerar a tranquilidade necessária à partilha "conspirativa". O que estou chamando de imprevisibilidade é o oposto da rigidez de uma narração presa apenas à forma superficial do texto. (GIRARDELLO, 2004, p 05).

Faz- se necessário também a adequação da história “[...] ao espaço criado pela imaginação infantil." (TAHAN, 1964, p. 73). O rigor deve estar presente na escolha da história que deve: despertar emoções, estimular a imaginação, basear-se na verdade e ter uma forma, quanto possível, perfeita (TAHAN, 1964) e que possibilite aos alunos a compreensão da sequência lógica de uma narrativa.

A expressão facial, o olhar, a voz e a expressão corporal são elementos que vão dando vida à história e esses são construídos a partir da sensibilidade do narrador e ao compreender de forma livre que a performance não é preparação para algo que será cobrado na sequência, mas sim que a experiência de escutar uma narrativa, "[...] contribui para que as crianças possam forjar, pouco a pouco, um rico arsenal de imagens internas alimentadas pela arte da palavra, tanto oral como escrita." (MACHADO, 2015, p. 49).

E neste fio é que se une a fala e a escuta, permeado pelo arsenal performático do narrador que não é teatralização de uma história, mas narração de uma história. Diante do exposto, será que o espaço dado à narrativa tem a função que lhe é cabível ou apresenta-se como coadjuvante? Com base nesses questionamentos o próximo item versará sobre uma pesquisa de campo com o objetivo de analisar a visão do professor sobre a contribuição das narrativas para a aprendizagem.

\section{Narrativa oral e a aprendizagem: a visão do professor}

A pesquisa que foi realizada em um município do Sul do Paraná, constitui-se do tipo amostragem não probalística, a partir de um questionário via formulário google docs direcionado aos professores da rede municipal de ensino, especificamente da pré-escola (infantil cinco) e do primeiro ano, dos anos iniciais. As perguntas que versaram o questionário e que delimitaram as temáticas que serão apresentadas foram: sobre a utilização das narrativas orais na prática pedagógica e quando utiliza; como faz a narrativa oral de histórias e se utiliza algum material; para que utiliza a narrativa de história; qual sua contribuição. 
Foi solicitada a autorização à Secretaria Municipal de Educação que disponibilizou os questionários aos sujeitos via e-mail. Foram enviados para trinta e três sujeitos, tendo retorno de doze respostas. Uma vez que a pesquisa era por amostragem, esse número de respostas, mesmo que em número menor, forneceu reflexões preponderantes para os questionamentos da pesquisa e reflexões, bem como planejamento de futuras ações e pesquisas.

Conforme as respostas sobre a utilização das narrativas orais em sala de aula, verificou-se que $92 \%$ utilizam-nas pelo menos uma vez por semana. Todavia ao serem questionados sobre como fazem as narrativas observa-se nas repostas que não está clara a diferença entre narrar, ler e dramatizar, assim, é possível que essa percentagem diminui dado a fragilidade em conceituar o que é narrativa oral de histórias.

Gráfico 01 - Uso de material nas narrativas orais

\section{4- Nas narrativas orais de histórias, você utiliza algum material?}

12 respostas

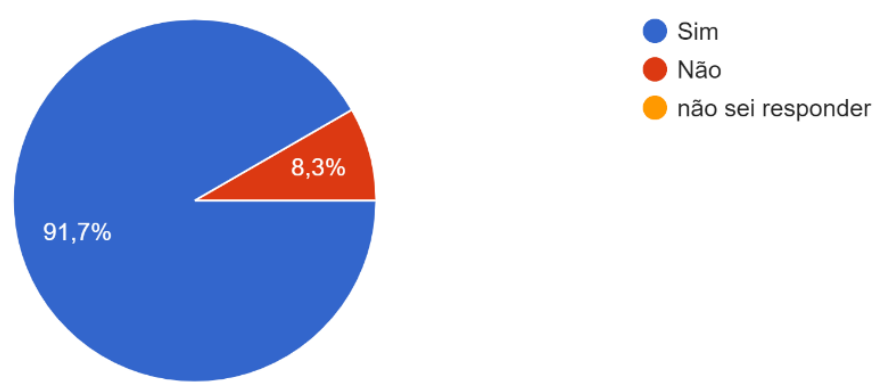

Fonte: Elaborado pelas autoras.

Esse dado pode ser averiguado ao apontarem (97\% das repostas) que utilizam material de apoio: livros, livro digital, avental de histórias, folhas ilustrativas fantoches e caracterização de personagem. Dessas respostas, apenas um participante aponta que não usa nenhum recurso. A intenção dessa pergunta era verificar se sabiam as características da narrativa oral de história, questão que muitas vezes é confundida e que direciona ao outro questionamento que versa sobre a sua contribuição, uma vez que

Contar um conto não é ler um conto. A leitura em voz alta é uma atividade enriquecedora e muito apropriada para despertar o gosto pelos livros, mas, no âmbito em que trabalha o narrador, costuma ter algumas limitações. Também não é dizer um monólogo teatral. Além do mais, a fronteira entre uma e outra atividade é ambígua[...]. Ao narrar um conto empregamos nossas palavras, que podem ser diferentes a cada vez que contamos. (ORTIZ, 2004, p 104). 
Uma das contribuições das narrativas orais de histórias é possibilitar que a criança desenvolva a sua imaginação criativa, como já foi apontado anteriormente. Por isso, o ato de contar história não necessita do auxílio de outro recurso a não ser os gestos, a voz e o corpo do narrador, pois “[...] contar não é só dizer um texto.” (SISTO, 2005 p. 42). É importante a preparação do contador de histórias, pois essa atividade muitas vezes é confundida com o ler histórias. Ler e contar são situações diferentes e envolvem conteúdos diferentes, muito embora seja comum não haver essa distinção, assim como é errôneo pensar que ao dramatizar uma história, com um arsenal de fantoches, dedoches ou fantasias, estaria contando uma história.

Ler, dramatizar e narrar, cada um tem seus objetivos específicos e todos desenvolvem vários aspectos, porém "Tão atraente quanto as figuras do livro pode ser a linguagem que usarmos: a sonoridade das palavras, os estribilhos, as rimas e repetições, o uso de diferentes vozes ou sotaques para os personagens (GIRARDELLO, 2004, p 07), que as narrativas orais de história, haja vista que seu foco é a audição, potencializa ao oportunizar a simples escuta de histórias.

Muito embora pareça óbvio essa diferença e a contribuição para a imaginação criativa, esta não foi o foco das respostas apontadas pelos sujeitos da pesquisa, ao ser perguntado qual seria a contribuição para a alfabetização. Das repostas emergiram as seguintes temáticas: interesse pela leitura, interpretação, oralidade, desenvolvimento da escrita, sequência lógica das ideias, enriquecimento do vocabulário, função social da escrita, formação da personalidade e criatividade. Constatase que o contar histórias está muito relacionado com a leitura de histórias, pois pelas repostas verifica-se que o eixo leitura e escrita, está presente na maioria delas.

Certamente, mesmo que não seja solicitado alguma forma de registro para as crianças após a contação de histórias, o simples fato de ouvir e possibilitar as narrativas das próprias crianças, proporciona de forma potencial que as mesmas desenvolvam a habilidade da oralidade, principalmente em relação ao vocabulário, os referenciais forno articulatórios, a sequência lógica de ideias, a reflexão sobre a palavra falada e seus referenciais fonológicos, bem como as imagens mentais das palavras, entre outros aspectos que envolvem a íntima relação entre leitura, escrita e oralidade. Caracteriza-se como uma estratégia pedagógica preponderante para instrumentalizar as crianças para o desenvolvimento das práticas de linguagem e que na sequência dos usos das narrativas em sala de aula tornar-se-ão real na criança, pois como já foi apontado o pensamento vai se tornando lógico a partir do momento que é dado oportunidade às crianças para refletirem sobre a linguagem

Uma reflexão que suscitou destas temáticas apontadas é sobre o conceito de alfabetização, visto que a pergunta era direcionada para essa etapa de ensino. Verificou-se nas respostas, a visão da alfabetização como algo que se resume à uma técnica sistematizada de aprendizagem da linguagem escrita. A maioria das respostas estava relacionada a esse aspecto, com poucas menções sobre 
os aspectos simbólicos das histórias, que são alimento para a imaginação criativa. Entretanto, ao ser apontado que a narrativa oral desenvolve interpretação, sequência lógica de ideias e a formação da personalidade e da criatividade, o foco é direcionado para além dos aspectos pragmáticos da aquisição do sistema de escrita alfabética.

Muito embora aspectos relacionados aos que foram apresentados foram apontados nas respostas dos sujeitos, o espaço dado às narrativas orais não se caracteriza como protagonista e sim coadjuvante, pois ao serem indagados para que utilizam as narrativas orais, observou-se que são para fins pretextais.

\section{Gráfico 02 - Uso das Narrativas Orais}
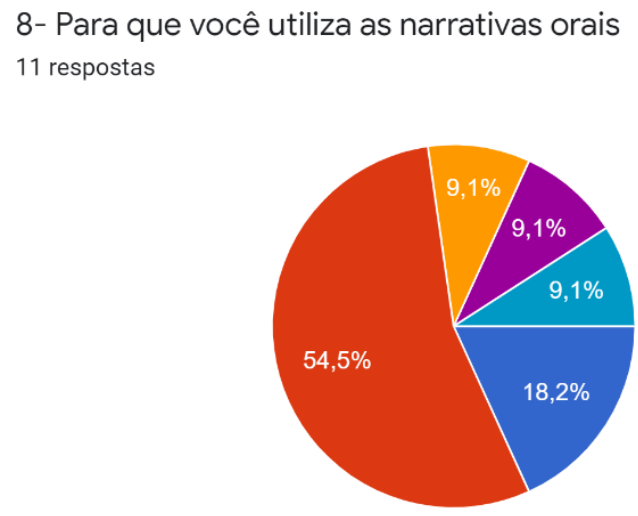

Em projetos específicos ( ex. Hora do conto)

Para introduzir ou complementar um tema de estudo

Para volta a calma

Para o desenvolvimento de aspectos específicos relacionados às narrativas.

Sempre que necessário, além utilizar nas situações a acima, utilizo para mo..

Para o desenvolvimento global da cria...

Fonte: Elaborado pelas autoras.

Apesar de haver o entendimento da contribuição das narrativas nos seus vários aspectos já abordados acima, são sempre consideradas como veículos para outra questão pedagógica a ser trabalhada, como uma história que tenha relação com o conteúdo que será trabalhado, projetos específicos, na introdução de temas com fundo moral, datas comemorativas, entre outros.

Não está sendo feita uma crítica e nem condenando o fato da utilização das narrativas orais como estratégia pretextais, mas que lhes deixar em segundo plano, como apenas instrumento para outro trabalho ou para deixar a atividade mais interessante, lúdica e prazerosa é desconsiderar o seu estatuto próprio e as possibilidades que proporciona para o desenvolvimento humano.

\footnotetext{
Muitas vezes, os educadores parecem tão preocupados com os conteúdos que não percebem as possibilidades dessa prática em si mesma; com o intuito de se utilizarem deste momento como mera ferramenta que em si não traz nada notável, a não ser dourar a pílula da matéria a ser ensinada, acabam desprezando o seu verdadeiro caráter educativo. (BELLO, 2004, p. 161).
} 
Defende-se a necessidade de apontar a narrativa oral, ou contação de histórias, para além do pragmatismo pedagógico e esta pesquisa demonstrou, a partir das fragilidades expostas na coleta de dados, um rico espaço para formação docente, bem como referenciais a serem discutidos.

Muito mais que pretexto para um conteúdo ou pano de fundo para outras estratégias didáticas, a narrativa oral de história é o espaço interativo e sugestivo no qual a palavra, em seu caráter dialógico (BAKTHIN, 2006), concretiza-se como arsenal para o desenvolvimento da imaginação criativa e consequentemente o processo específico do ser humano que é a antecipação da ação. Essa questão deve ser o foco principal das discussões sobre as narrativas orais de histórias como pressuposto epistemológico e, a partir desses, os pressupostos metodológicos.

As fragilidades apontadas na pesquisa de campo apontam para a necessidade de um espaço formativo que potencialize os professores como narradores de histórias nas especificidades que o ato de contar histórias constitui-se, tanto ao que se refere às questões epistemológicas, como às questões técnicas. Outrossim, é preponderante que o espaço universitário possibilite ações de acesso às discussões nas várias temáticas sociais que podem fomentar o posicionamento político do narrador, pois antes de qualquer questão metodológica, a contação de história é um ato político de dar voz às histórias, principalmente àqueles que não têm acesso ao saber elaborado pela humanidade e que é direito de todo cidadão, bem como divulgar essa prática, muitas vezes infantilizada, como potencializadora para a emancipação humana.

\section{Considerações finais}

O presente texto discutiu sobre as narrativas orais de histórias com a finalidade de dimensionar a contribuição dessa prática para além dos aspectos pragmáticos que normalmente está atrelada no espaço escolar.

Pretendeu-se expor reflexões que apontassem a relação entre o ato de contar histórias, a constituição do sujeito e sua humanização e o quanto a linguagem e a imaginação criativa são primordiais para a humanização e podem ser potencializadas a partir das contações de histórias.

Com efeito, os alunos, ao serem expostos a essa prática, têm acesso às reflexões sobre a linguagem, tanto aos aspectos que envolvem a leitura, escrita e oralidade como a produção de sentidos, fato que está bem claro nas respostas apresentadas pelos sujeitos da pesquisa de campo. A partir dos dados coletados, verifica-se que a narrativa oral de histórias não é considerada em seu pressuposto epistemológico, sendo relegada para segundo plano, cerceando a oportunidade dos alunos terem acesso à essa forma de concretização da linguagem humana e de um saber elaborado pelo homem. 
Neste sentido, ao não ser dado o devido valor à narrativa oral de história em sua especificidade como saber e como parte da condição humana, o professor, em seu planejamento, não organiza ações que envolvem as narrativas com objetivos de potencializar o desenvolvimento da linguagem e da imaginação criativa, imprescindíveis para ação humana, enquanto ação com intencionalidade e transformadora. A mediação, enquanto categoria e possibilidade de intervenção pedagógica, que as narrativas podem proporcionar, tornam-se mais um pretexto do que a própria ação desenvolvente. Diante disso, a análise dos dados apontou fragilidades no fazer docente e reflexões pertinentes para a necessidade e importância de espaços de formação, debates e experiências.

\section{Referências}

BAKHTIN, M.; VOLOCHÍNOV, V. Marxismo e filosofia da linguagem. Tradução de Michel Lahud e Yara Frateschi Vieira. 12. ed. São Paulo: Hucitec, 2006.

BELLO, S. C. Por que devemos contar histórias na escola? In: GIRARDELLO, G. (Org.). Baús e chaves da narração de histórias. 2. ed. Florianópolis: SESC/SC, 2004.

BENJAMIN, W. Magia e técnica, arte e política: ensaios sobre literatura e história da cultura. Tradução de Sérgio Paulo Rouanet. 7. ed.. São Paulo: Brasiliense, 1994. p. 197-221. (Obras escolhidas, v.1).

COELHO, B. Contar histórias uma arte sem idade. 10.ed. São Paulo: Ática, 1999.

GIRARDELLO, G. Vož, presença e imaginação: a narração de histórias e as crianças pequenas. Florianópolis: Universidade Federal de Santa Catarina; Programa de Pós-Graduação em Educação, 2004. Disponível em: http://nica.ufsc.br/index.php/publicacoes/gilka. Acesso: 14 jan. 2021.

GIRARDELLO, G. Voz, presença e imaginação: a narração de histórias e as crianças pequenas. In: FRITZEN C., CABRAL G. S. Infância: imaginação e educação em debate. Campinas-SP: Papirus; 2007 . p.39-57.

GIRARDELLO, G. Uma clareira no bosque: contar história na escola. Campinas-SP: Papirus, 2014.

LURIA, A. R. Vigotskii. In: VIGOTSKII, L. S.; LURIA, A. R.; LEONTIEV, A. N. Linguagem, desenvolvimento e aprendizagem. 15. ed. São Paulo: Ícone, 2017.

MATOS, G. A; SORSY, I. O ofício do contador de histórias: perguntas e respostas, exercícios práticos e um repertório para encantar. 3. ed. São Paulo: Martins Fontes, 2009.

MARCUSCHI, L. A. Da fala para a escrita atividades de retextualização. 4. ed. São Paulo: Cortez, 2003.

MARTINS, L. M. O desenvolvimento do psiquismo e a educação escolar: contribuições à luz da Psicologia Histórico - Cultural e da Pedagogia Histórico Crítica. Campinas-SP: Autores Associados, 2013.

MARX, K. Manuscritos-econômicos filosóficos. São Paulo: Boitempo, 2004. 
MARX, K; ENGELS, F. A ideologia Alemã. São Paulo: Boitempo, 2007.

MARX, K. O Capital: crítica da economia política. 2. ed. São Paulo: Boitempo, 2017. v. I.

ORTIZ, E. Ler, interpretar e recitar... In: GIRARDELLO, G. (Org.). Baús e chaves da narração de bistórias. 2 ed. Florianópolis: SESC/SC, 2004.

SISTO, C. Textos e pretextos sobre a arte de contar histórias. 2. ed. Curitiba-PR: Ed. Positivo, 2005.

SISTO, C. O misterioso momento: a história do ponto de vista de que ouve (e também vê!). In: GIRARDELLO, G. (Org.). Baús e chaves da narração de histórias. 2 ed. Florianópolis: SESC/SC, 2004.

SODRÉ, N. W. História da Imprensa no Brasil. 4. ed. Rio de Janeiro: Mauad, 1999.

TAHAN, M. A arte de ler e contar histórias. 4. ed. Rio de Janeiro: Conquista, 1964.

VIGOTSKI, L.S. O desenvolvimento psicológico na infância. São Paulo: Martins Fontes, 1999.

VIGOTSKI, L.S. A imaginação e a criança na infância: ensaio psicológico livro para professores. Tradução de Zóia Prestes e Elizabeth Tunes. São Paulo: Expressão Popular, 2018. 